\title{
SISTEM INFORMASI GEOGRAFIS LAHAN PERKEBUNAN KARET DI KABUPATEN MERAUKE BERBASIS WEB
}

\author{
Nilfred Patawaran, Fransiskus Xaverius Manggau \\ Email : nilfred@unmus.ac.id, Fransiskus@unmus.ac.id \\ Jurusan Teknik Informatika, Fakultas Teknik \\ Universitas Musamus Merauke
}

\begin{abstract}
ABSTRAK
Potensi perkebunan karet dikabupaten Merauke di dukung oleh keadaan alam serta iklim yang baik untuk pengembangan perkebunan karet. Kurangnya informasi pengembangan perkebunan karet di Kabupaten Merauke yang diharapkan melibatkan investor, sampai saat ini masih menjadi tantangan untuk mancari solusi pemecahannya, berdasarkan masalah tersebut maka diperlukan Sistem informasi berbasis web dapat mambantu publikasi serta promosi potensi produksi dan pengembangan perkebunan karet di Kabupaten Merauke.

Pembuatan aplikasi SIG (Sistem Informasi Geografis) menggunakan Google Map serta MySQL (MyStructure Query Language), Metode penelitian yang digunakan adalah Pengumpulan data lokasi, luas lahan, produksi dan lokasi pengembangan lahan perkebunan karet, Perancangan, Analisa data dan Pengujian dilakukan dengan Metode Black Box dengan menggunakan kuisioner. Informasi yang diberikan berupa informasi lokasi, luas lahan, produksi dan lokasi pengembangan lahan perkebunan karet di Kabupaten Merauke.

Aplikasi Sistem Informasi Geografis Lahan Perkebunan Karet Di Kabupaten Merauke Berbasis Web. Aplikasi ini dapat mambantu publikasi serta promosi potensi produksi dan pengembangan perkebunan karet di Kabupaten Merauke. Perancangan Sistem Informasi Geografis dengan Google Map memberikan tampilan informasi berupa data lokasi, luas lahan, produksi dan lokasi pengembangan lahan perkebunan karet yang mudah di akses.
\end{abstract}

Kata kunci : Sistem Informasi Geografis, Karet, Lahan, Web.

\section{PENDAHULUAN}

Kabupaten Merauke memiliki luas wilayah seluas $\pm 45.071 \mathrm{Km}^{2}$ dan luas lahan yang potensial untuk perkebunan seluas 1.434.250 Ha. Dari luasan tersebut yang baru dimanfaatkan untuk usaha perkebunan seluas $26.118 \mathrm{Ha}$.

Belum ada media publikasi akan lokasi dan potensi perkebunan karet sehingga belum maksimalnya pemerintah daerah mempromosikan potensi produksi dan pengembangan perkebunan karet di Kabupaten Merauke.

Pokok permasalahan di atas penulis menawarkan suatu solusi melalui pembuatan skripsi ini untuk membuat suatu sistem informasi geografis. Sehingga dibuat suatu Sistem Informasi Geografis Pemetaan Lahan Perkebunan Karet Di Kabupaten Merauke Berbasis Web. "Sistem Informasi Geografis Pemetaan Lahan Perkebunan Karet Di Kabupaten Merauke Berbasis Web" Diharapkan dapat sebagai media publikasi dan
Promosi akan lokasi, potensi perkebunan karet dan rencana pengembangan perluasan areal karet yang diharapan ada investor dari luar Kabupaten Merauke yang akan menenamkan modal dan mengembangkan produksi perkebunan keret di kabupaten Merauke.

RUMUSAN MASALAH :

1. Bagaimana mambangun suatu sistem informasi geografis berbasis web pemetaan lahan perkebunan karet yang memberikan informasi lokasi, luas lahan, dan produksi karet?

2. Bagaimana menyediakan informasi lokasi rencana pengembangan lahan perkebunan karet di kabupaten Merauke yang berbasis web?

\section{TUJUAN PENELITIAN :}

1. Membangun suatu sistem informasi geografis berbasis web pemetaan lahan perkebunan karet yang 
memberikan informasi lokasi, luas lahan, dan produksi karet.

2. menyediakan informasi lokasi rencana pengembangan lahan perkebunan karet di kabupaten Merauke yang berbasis web.

\section{TINJAUAN PUSTAKA}

Sistem informasi geografis ini sebelumya sudah banyak di buat, tetapi tempat dan program aplikasinya yang di gunakan berbeda-beda. Adapun sistem informasi geografis adalah sebagai berikut :

1. Akhmad Suhadak, Teknik Informatika Malang 2010, Penelitian Dilakukan Kantor Dinas Pertanian, " Sistem Informasi Geografis Lahan Pertanian Kabupaten Banyuwangi” Dalam penyusunan tugas akhir ini menggunakan MS4W sebagai modul yang digunakan untuk membuat fungsi dan class MapServer agar dapat dijalankan di PHP/Mapscript. Sedangkan MapServer sendiri adalah sebuah layanan untuk memproses dan menampilkan data spasial yang berasal dari database. Untuk apalikasi databasenya akan menggunakan PostgreSQL yang sudah mendukung tipe data spasial. pemanfaatannya digunakan untuk membantu masyarakat untuk mengetahui informasi tentang segala sesuatu yang menyangkut tentang pertanian.

2. Hanisa Aulia (2011) judul penelitian "Sistem Informasi Geografi Objek Wisata Di Kabupaten Magelang". Dalam penelitian ini sistem aplikasi yang digunakan ArcView 3.3.dan MySql. Dalam penelitian ini sistem yang dibuattampilan informasi tata letak objek wisata dan keterangan objek wisata.

\section{METODE PENELITIAN}

Metode yang digunakan dalam penelitian ini adalah sebagai berikut:

\section{METODE PENGUMPULAN DATA}

1. Metode Wawancara

Wawancara adalah penulis menanyakan langsung beberapa pertanyaan kepada pihak-pihak yang terkait yaitu staf Kantor Dinas Kehutanan dan Perkebunan Kabupaten Merauke untuk memperoleh data-data yang diperlukan.

2. Studi kepustaka

Studi Pustaka Yaitu melakukan pencarian terhadap buku-buku yang berkaitan dengan penelitian.

\section{PERANCANGAN}

Perancangan Yaitu melakukan perancangan program yang akan diinformasikan dengan.

a. Data Flow Diagram (DFD).

b. Perancangan antarmuka (interface).

c. Perancangan database pada sistem atau aplikasi website yang dibuat.

2. Analisa data yaitu melakukan analisa data dengan menggunakan kuisoner untuk menguji program yang dibuat

3. Pengujian

Pengujian dilakukan dengan Metode Black Box dengan menggunakan kuisioner.

\section{PERANCANGAN SISTEM}

Tahapan ini akan dilakukan perancanagn pemodelan fungsional sistem secara keseluruhan. Dapat digambar sebagai berikut:

\section{DIAGRAM KONTEKS}

Proses perancanagan dimulai dengan pembuatan Diagram Konteks. Diagram Konteks menggambarkan suatu sistem secara global dan sederhana.

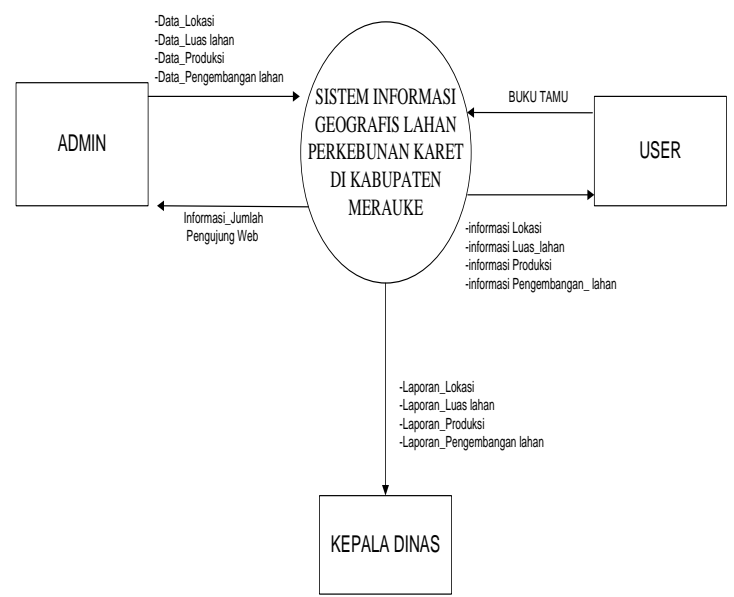

Gambar 3.1. Rancangan diagram konteks

4. IMPLEMENTASI DAN PENGUJIAN SISTEM

IMPLEMENTASI INTERFACE 
Implementasi merupakan proses pengubahan sistem yang telah dirancang kemudian diterapkan dalam program. Pada tahap ini digunakan dengan menuliskan script dan pembuatan interface. akan tampil interface menu utama berisi tiga tombol menu yaitu tombol User, Dan Admin. Pada tombol menu user program bisa langsung digunakan. Kemudian akan tampil interface selamat datang dan masuk ke dalam interface menu pilihan informasi berisi tombol menu pilihan yaitu tombol sub menu informasi perkantoran. Tombol login pada interface menu utama akan menampilkan interface login kewenangan dalam perubahan dan penambahan data dan memiliki password untuk dapat masuk ke dalam program. Dalam pengoperasiannya Admin hampir sama dengan user, hanya saja jika menggunakan tombol user dapat langsung login tidak dapat perlu mengetikkan password.

\section{INTERFACE MENU UTAMA}

Interface menu utama merupakan tampilan awal pada saat program pertama kali dibuka. Dalam interface menu utama berisi menu-menu diantaranya adalah Home ,Informasi Karet, Kontak, Peta dan admin. Untuk menu user merupakan login langsung penggunaan program, dan menu admin merupakan menu masuk program yang memiliki password.

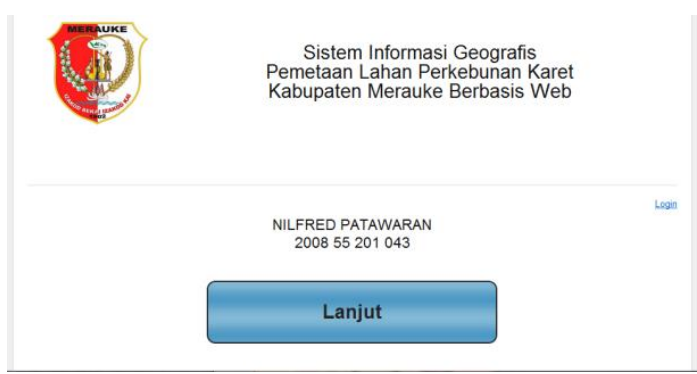

Gambar 4.1. InterfaceMenu Utama

\section{INTERFACE MENU HOME}

Interface menu Home merupakan interface menu Home yang didalamnya berisi profil Dinas kehutanan dan perkebunan, Visi dan Misi , Struktur organisasi serta uraian tugas.

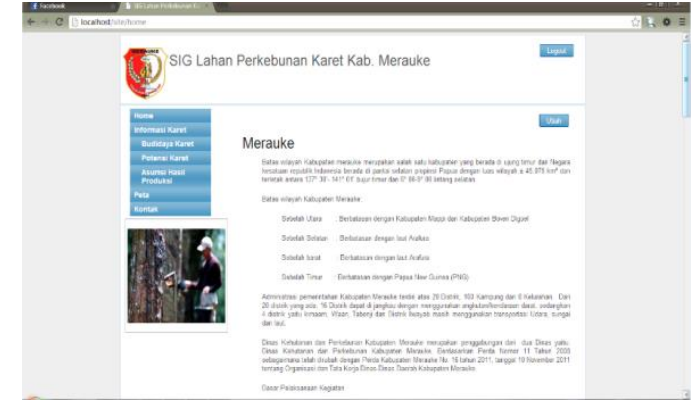

Gambar 4.2. Interface Menu Home

\section{INTERFACE INFORMASI KARET}

Interface informasi karet berisi menu tampilan Desain interface informasi karet berisi tentang budidaya karet, potensi karet di Kabupaten Merauke dan sertai Asumsi Pencapaian Hasil dan Produksi Perluaan Karet Seluas $1 \mathrm{Ha} /$ Tahun.

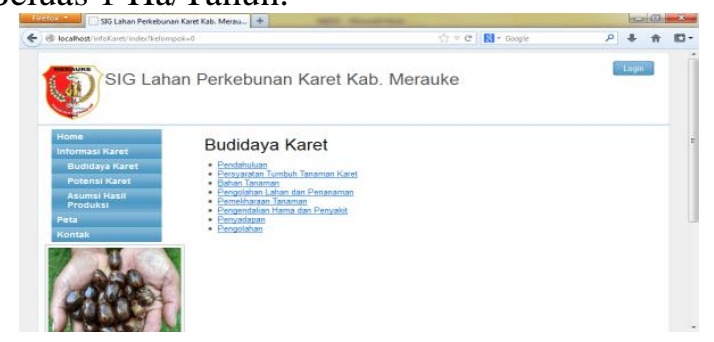

Gambar 4.3. Interface Menu Informasi karet(Budidaya Karet)

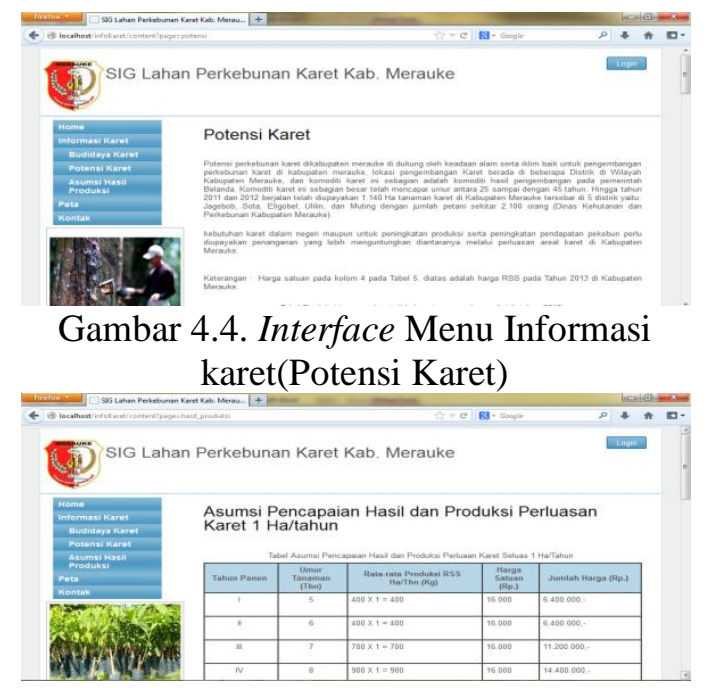

Gambar 4.5. Interface Menu Informasi karet(Asumsi Hasil Produksi )

\section{INTERFACE PETA}

Interface listing data buku tamu digunakan Interface Peta berisi Desain interface Peta berisi Lokasi, Luas lahan, Produksi Karet dan Rencana pengembangan lahan. 


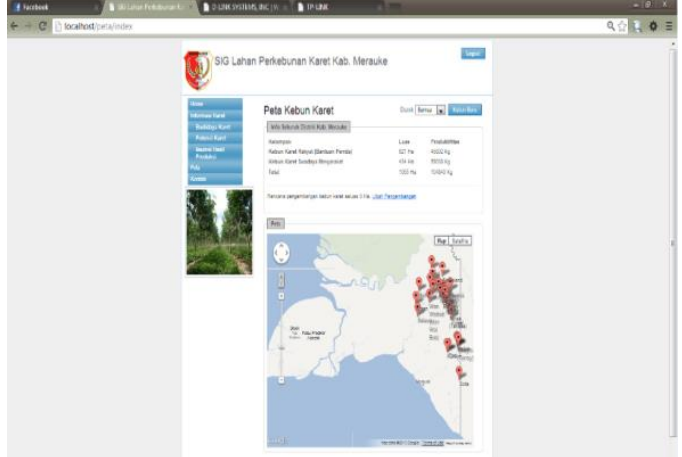

Gambar 4.6. Interface Peta

\section{INTERFACE MENU KONTAK}

Interface menu kontak berisi menu tampilan Kontak kami. Tampilan Kontak kami berisi nama, alamat, email, topik, pesan, dan tombol submit.

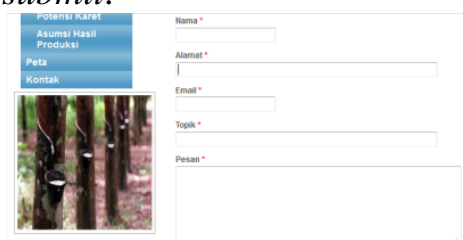

cetesi

Gambar 4.7. Interface Menu Kontak

\section{PENGUJIAN}

Pengujian sistem dilakukan untuk mendefinisikan kesalahan program yang diakibatkan oleh kesalahan logika program sehingga terjadi penghentian program secara tidak normal. Pengujian sistem ini dilakukukan dalam dua cara yaitu pengujian Black Box dan Kuisioner.

\section{PENGUJIAN BLACK BOX}

Pengujian Black Box bertujuan untuk menguji komponen sistem yang telah dirancang sebelumnya dan untuk memastikan bahwa setiap elemen dari sistem telah berfungsi sesuai dengan yang diharapkan.

Pengujian yang berfokus pada persyaratan atau kebutuhan perangkat lunak yang dibuat.

\section{KUISIONER}

Pengujian program ini dilakukan oleh 30 orang responden. Responden menjalankan program yang selanjutnya mengisi daftar pertanyaan (kuisioner) sebagai respon terhadap kinerja sistem yang dibangun.

1. Hasil uji coba mengenai format tampilan program.

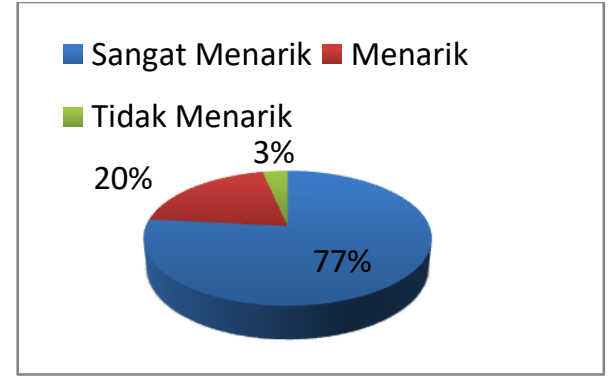

Gambar 4.8. Grafik format tampilan program

Hasil kuisioner tentang format tampilan program diperoleh informasi sebagai berikut, 23 (77\%) responden menjawab sangat menarik, $6(20 \%)$ responden menjawab menarik dan 1 (3\%) responden yang menjawab tidak menarik.

2. Hasil uji coba mengenai Kecepatan akses dalam menampilkan, menginput data dan informasi.

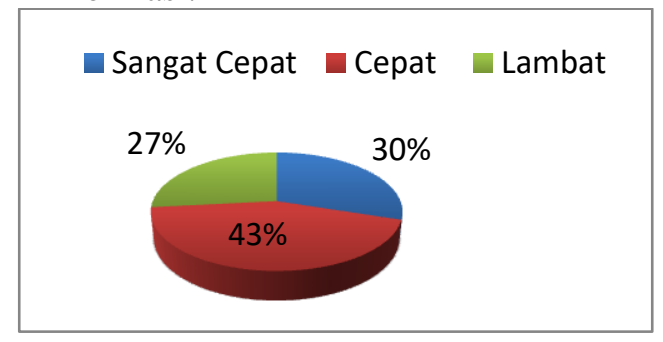

Gambar 4.9. Grafik Kecepatan akses.

Hasil kuisioner tentang Kecepatan akses diperoleh informasi sebagai berikut, 9 (30\%) responden menjawab sangat cepat, 13 (43\%) responden menjawab cepat dan 8 (27\%) responden menjawab lambat.

3. Hasil uji coba mengenai kompleksitas data dan informasi.

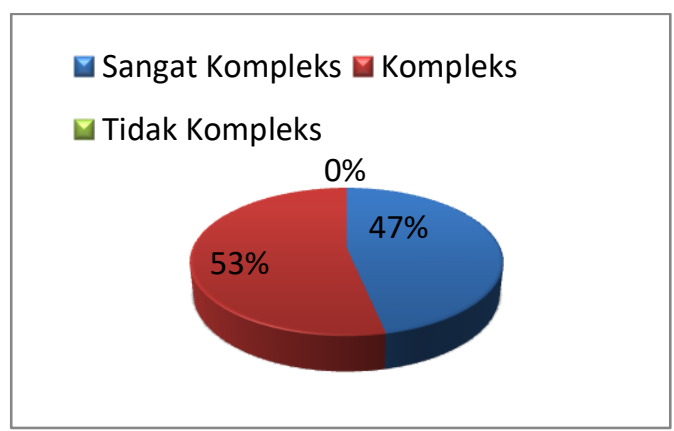

Gambar 4.10. Grafik hasil kompleksitas data dan informasi

Hasil kuisioner tentang kompleksitas data dan informasi diperoleh informasi sebagai berikut, $14(47 \%)$ responden menjawab sangat baik, $16(53 \%)$ responden menjawab baik dan 0 (27\%) responden menjawab kurang baik. 
4. Hasil uji coba mengenai Kemudahan dalam menjalankan progaram.

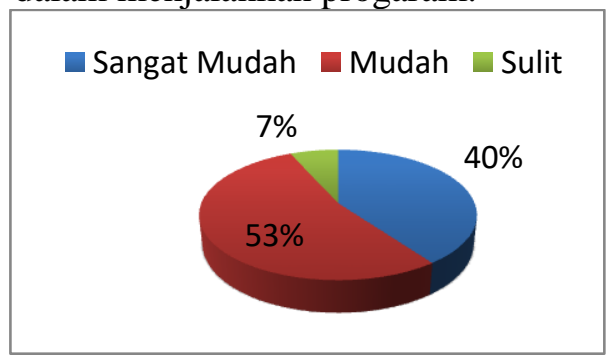

Gambar 4.11. Grafik kemudahan dalam menjalankan program

Hasil kuisioner tentang kemudahan dalam menjalankan program diperoleh informasi sebagai berikut, $12(40 \%)$ responden menjawab sangat mudah, $16(53 \%)$ responden menjawab mudah dan 2 (7\%) responden yang menjawab sulit.

\section{PENUTUP KESIMPULAN}

Berdasarkan hasil penelitian dan pengujian sistem , maka dapat ditarik beberapa kesimpulan antara lain :

1. Aplikasi SIG pemetaan lahan perkebunan karet di Kabupaten Merauke dengan menggunakan google map dapat memberikan informasi lokasi, luas lahan, produksi karet dan rencana pengembangan lahan perkebunan karet di kabupaten Merauke yang berbasis web dapat mambantu publikasi serta promosi potensi produksi dan pengembangan perkebunan karet di Kabupaten Merauke yang diharapan ada investor dari luar Kabupaten Merauke yang akan menenamkan modal dan mengembangkan produksi perkebunan keret di Kabupaten Merauke.

2. Pengolahan data yang Pengolahan data yang dilakukan hanya dilakukan oleh admin yang mempunyai hak akses sistem berupa akses untuk mengolah data lokasi, luas lahan, produksi karet dan rencana pengembangan lahan perkebunan karet berdasarkan hasil penelitian dan implementasi sistem.

\section{SARAN}

Berdasarkan hasil penelitian yang dilakukan, bahwa didalam penelitian ini masih terdapat kekurangan sebagai berikut :
1. Peta perkebunan karet masih kurang mendetail dan pengembangan selanjutnya diharapkan tersedia peta jalan yang lebih mendetail agar dapat mempermudah dalam menentukan lokasi pada peta.

2. Aplikasi ini memerlukan Jaringan internet yang baik agar dapat menampilankan peta sehingga diharapkan dalam pengembangannya menggunakan peta yang offline atau berbasis desktop agar tidak mempengaruhi tampilan peta.

\section{DAFTAR PUSTAKA}

Barus dan Wiradisastra, 2000 Sistem Informasi Geografi, Laboratorium Penginderaan Jauh dan Kartografi, Jurusan Tanah, Bogor.

Bin Ladjamudin, Al Bahra, 2006, Rekayasa Perangkat Lunak, Graha Ilmu, Yogyakarta.

Budhi Irawan, 2005, Jaringan Komputer, Graha Ilmu, Yogyakarta

Dinas Kehutanan dan Perkebunan Kabupaten Merauke, 2012, Profil Dinas Kehutanan dan Perkebunan Kabupaten Merauke,Merauke.

Dinas Kehutanan dan Perkebunan Kabupaten Merauke, 2012, Data Statistik Dinas Kehutanan dan Perkebunan Kabupaten Merauke, Merauke.

Hartono, Jogiyanto. 2000. Pengenalan Komputer : Dasar Ilmu Komputer, Pemograman, Sistem Informasi, dan Intelegensi Buatan. Edisi 3. Cet. Kedua. Andi Offset, Yogyakarta.

Hartono, Jogiyanto. 2005. Analisis dan Desain Sistem Informasi, Edisi III. Andi Offset, Yogyakarta

Hartono, Jogiyanto . 2006. Analisis Perancangan Sistem Informasi. Andi Offset. Yogyakarta

Kristianto, Andri. 2004. Rekayasa Perangkat Lunak (Konsep Dasar). Gava Media, Yogyakarta.

Pressman, Roger S,1997, Software Engineering (a practitioner's approach), McGrawHill. New York

Purwadhi, 1994. Interpretasi Citra Digital, Grasindo, Jakarta.

Pusat Penelitian dan Pengembangan Perkebunan, 2010, Budidaya dan Pasca Panen Karet, Bogor 